Vietnam Academy of Science and Technology
Vietnam Journal of Earth Sciences
http://www.vjs.ac.vn/index.php/jse

\title{
Study of impurity in blue spinel from the Luc Yen mining area, Yen Bai province, Vietnam
}

\author{
Le Thi Thu Huong*1,2, Tobias Haeger ${ }^{3}$, The-Long Phan ${ }^{4}$ \\ ${ }^{1}$ Faculty of Geology, VNU University of Science, 334, Nguyen Trai, Hanoi \\ ${ }^{2}$ Institut of Earth science, Karl Franzens University, Universitaetsplatz 2, 8010-Graz, Austria \\ ${ }^{3}$ Institute of Geosciences, Johannes Gutenberg University, 55099- Mainz, Germany \\ ${ }^{4}$ Department of Physics, Hankuk University of Foreign Studies, Yongin 17035, South Korea
}

Received 6 March 2017; Received in revised form 24 October 2017; Accepted 28 November 2017

\begin{abstract}
In this paper, we present the main impurities in natural blue spinel from the Luc Yen mining area in Yen Bai province, Vietnam. Together with identifying impurities and their valence, we have taken into account the site of some impurities in the $\mathrm{MgAl}_{2} \mathrm{O}_{4}$ spinel structure by using sensitive techniques, including electron microprobe analysis (EMPA), UV-Vis-NIR, electron spin resonance (ESR), and X-ray absorption (XAS). EMPA results indicated that blue spinel contains different impurities, including V, Mn, Ni, Zn, Ti, Cr, Fe, Co and Ca. UV-Vis-NIR, ESR and XAS studies revealed that the oxidation state of $\mathrm{Mn}, \mathrm{Co}, \mathrm{Fe}$ and $\mathrm{Ni}$ is $2+$ while that of $\mathrm{Cr}$ is $3+$. Particularly, $\mathrm{Co}^{2+}$, $\mathrm{Fe}^{2+}$, and $\mathrm{Cr}^{3+}$ ions are identified. They contribute to the color variation of the blue spinel samples. Our study also indicated $\mathrm{Co}^{2+}$ and $\mathrm{Cr}^{3+}$ located in the octahedral position of $\mathrm{Al}^{3+}$ of the $\mathrm{MgAl}_{2} \mathrm{O}_{4}$ structure.
\end{abstract}

Keywords: Blue spinel; impurity; coloration.

C2018 Vietnam Academy of Science and Technology

\section{Introduction}

The study about lattice defects and impurities in natural spinel has been carried out by some research groups to identify the origin of the color. For blue spinel, the coloring mechanism is very complex and has been a matter of intense debate because the color displays different hues and saturations, such as light to dark, greyish to violetish blue, greenish and cobalt blue. The same visibly appeared color

"Corresponding author, Email: letth80@gmail.com of stones could be resulted from different coloring mechanisms.

Prior to the study of Shigley and Stockton (1984), it was believed that iron is the main factor causing the blue color in natural spinel, whereas the detection of cobalt in the samples was a proof to the conclusion of synthetic origin. These authors, however, elucidated that both cobalt and iron attributed to the blue color in natural spinel. More recently, D'Ippolito et al. (2015) studied on the influence of $\mathrm{Co}$ and $\mathrm{Fe}$ on different blues of natu- 
ral spinel, and reported that the color of natural spinel is enhanced by the presence of $\mathrm{Co}$, even with a very low concentration. When iron and cobalt amounts are comparable, electronic transitions in cobalt have influence on the spinel color much stronger than those related to iron. Only when the Co content is extremely low (below $10 \mathrm{ppm}$ ), the total iron content has its main role in the color.

Particularly, according to Chauvire et al. (2015), $\mathrm{Co}^{2+}$ is the main chromophore of blue spinel from the Luc Yen area, Yen Bai province, Vietnam. The presence of $\mathrm{Fe}^{2+}$ makes the stone appeared greyer, and the hue of blue depends on iron/cobalt ratio. In our study, we based on UV-Vis spectroscopy to assess the valence of typical impurities, including $\mathrm{Cr}, \mathrm{Fe}$ and Co. We have taken into account the valence and the site of coloring impurities in blue spinel. We detected $\mathrm{Co}^{2+}, \mathrm{Fe}^{2+}, \mathrm{Mn}^{2+}$, $\mathrm{Ni}^{2+}$ and $\mathrm{Cr}^{3+}$. Performing Fourier transform for $\mathrm{Co}$ and $\mathrm{Cr} \mathrm{K}$-edge XAS spectra indicate $\mathrm{Co}^{2+}$ and $\mathrm{Cr}^{3+}$ ions occupying the octahedral site of the spinel structure. The color variation of Luc Yen blue spinel is discussed in details.

\section{Location and geologic background}

The Luc Yen district (Yen Bai province) is located $270 \mathrm{~km}$ north-west of the capital city Hanoi in northern Vietnam. The Yen Bai province is composed of two different geological units, namely the Lo Gam zone to the northeast and the Day Nui Con Voi to the southwest (Figure 1).

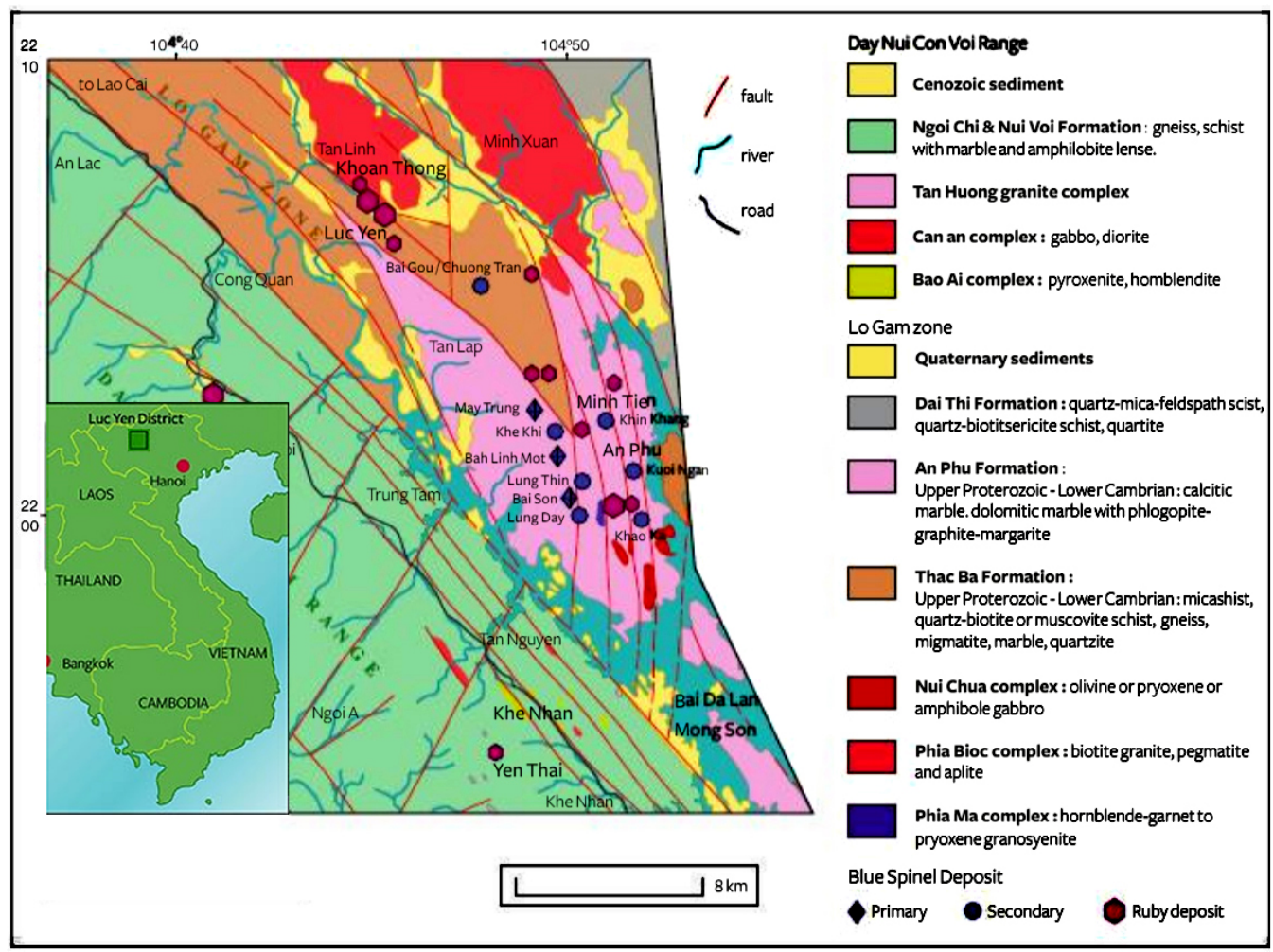

Figure 1. Local access and geological map of Luc Yen district (After Chauvire et al., 2015)

All of the gem deposits are located in the Lo Gam zone. The Lo Gam formation consists of a sedimentary series metamorphosed into marble, gneiss, calc-silicates, micaschist, and 
Vietnam Journal of Earth Sciences, 40(1), 47-55

amphibolite which are sometimes intruded by granitic and pegmatitic dykes (Leloup et al., 2001; Giuliani et al., 2003; Garnier et al., 2008). The marbles are mainly calcitic and interlayered with Al-, V-, and Cr-rich amphibolites.

Blue spinel is found in a layer of marble which is more than 500 meters thick. It occurs in discontinuous series of lenses, tens of millimeters thick and meter-sized in length, roughly following the regional foliation. Although ruby and spinel of other colors are also found in marbles but they are not associated with blue spinel.

\section{Materials and Methods}

\subsection{Material}

Two cobalt-blue spinel samples collected from the Luc Yen mining area (Yen Bai, Vietnam) were used for this study (Figure 2). They display homogeneous cobalt-blue color, and could be classified into two typical systems of lighter cobalt blue (denoted hereafter as LY-1) and saturate cobalt blue (LY-2). The LY-2 samples were extracted from marble host rock from Bai Son mine by the authors weighing $4.2 \mathrm{ct}$, while LY-1 samples were collected from alluvial in An Phu weighing $1.1 \mathrm{ct}$ and $7.3 \mathrm{ct}$. The samples were then cut into smaller pieces and polished for EMPA and UV-VIS-NIR studies. ESR and XAS measurements were performed on powder samples.

\subsection{Research methods}

Electron microprobe analysis (EMPA): Microscopic images were performed on an electron microscope (JEOL JXA-8900RL) equipped with energy-dispersive X-ray spectroscopy, using acceleration voltage of $20 \mathrm{kV}$ and filament current of $20 \mathrm{nA}$. Each sample was analysed 3 different positions to obtain the average composition. For most elements, the detection limit for wavelength-dispersive (WD) spectrometers is in the range of 30 300 parts per million (ppm).
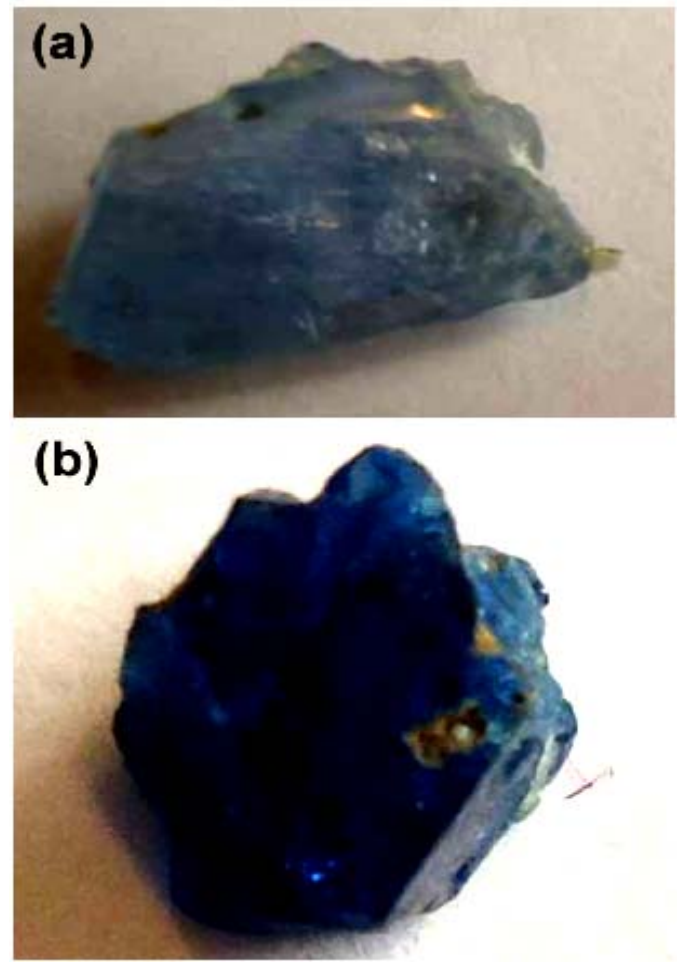

Figure 2. Original samples of (a) LY-1 and (b) LY-2 used in our study.

UV-Vis-NIR measurement: UV-Vis-NIR absorption spectra in the wavelength range of 200-1600 nm were recorded by using a Perkin Elmer Lambda 900 spectrophotometer. A sweeping speed of $300 \mathrm{~nm} / \mathrm{min}$ and a slit width $2.5 \mathrm{~mm}$ of the spectrometer were held during measurement. The data were analyzed by using the Perkin Elmer Spectrum V.5.0.1 program.

Electron spin resonance (ESR): ESR spectra were recorded by using a JEOL JESTE300 spectrometer. For this measurement, an amount $20 \mathrm{mg}$ of the samples in powder was loaded into a quartz-tube holder, and put in a microwave cavity of the ESR spectrometer. Microwave frequency was fixed at 9.45 $\mathrm{GHz}$ (within the $\mathrm{X}$ band), and the magnetic field $(H)$ could be swept from 0 to $10 \mathrm{kOe}$.

$X$-ray absorption spectroscopy: We used the extended X-ray absorption (XAS) tech- 
nique to investigate geometric and electronic structures of transition-metal impurities present in the samples. A light source was operated with energy of $2.5 \mathrm{GeV}$ and maximum current of $160 \mathrm{~mA}$. The spectra in the transmission configuration of some impurity $3 d$ elements for the $K$ edge, consisting of Ti (with the binding energy $\left.E_{0}=4966 \mathrm{eV}\right), \mathrm{V}\left(E_{0}=\right.$ $5465 \mathrm{eV}), \mathrm{Cr}\left(E_{0}=5989 \mathrm{eV}\right), \mathrm{Mn}\left(E_{0}=6539\right.$ $\mathrm{eV})$, Co $\left(E_{0}=7709 \mathrm{eV}\right)$, Fe $\left(E_{0}=7112 \mathrm{eV}\right)$ and $\mathrm{Ni}\left(E_{0}=8333 \mathrm{eV}\right)$ were checked. For reference, some foils and oxides of these elements were recorded under the same conditions. The analyses of XAS data afterwards were based on an IFEFFIT package.

\section{Results}

\subsection{EMPA analysis}

Chemical compositions of LY-1 and LY-2 obtained from EMPA analyses revealed that they are sensu stricto end members. Main chemical elements are $\mathrm{Al}$ and $\mathrm{Mg}$ with the amounts of respective oxides up to $70.48 \mathrm{wt} \%$ and $28.07 \mathrm{wt} \%$, respectively. The dominant impurities detected in these samples are $\mathrm{Fe}, \mathrm{Cr}$ and Ni. Other impurities include V, Mn, Zn, Ti, Co, and Ca. Particularly, LY-2 contains averagely $0.09 \mathrm{wt} \% \mathrm{Co}$, and $0.5 \mathrm{wt} \%$ Fe while LY-1 contains $0.05 \mathrm{wt} \% \mathrm{Co}$ and $0.71 \mathrm{wt} \% \mathrm{Fe}$, as shown in Table 1.

\subsection{UV-Vis-NIR}

UV-Vis-NIR spectra of LY-1 and LY-2 shown in Figure 3 reveal absorption peaks located in the ranges $500-650 \mathrm{~nm}$, and 400-500 $\mathrm{nm}$ (the violet-blue region). As indicated by Chauvire et al. (2015), the absorption peaks at $371,386,455$ and $590 \mathrm{~nm}$ are due to the electronic transitions of $\mathrm{Fe}^{2+}$ ions. Meanwhile, three intense absorption peaks at 550, 580 and $625 \mathrm{~nm}$ are associated with electronic transitions of $\mathrm{Co}^{2+}$ ions. Another weak peak at $\sim 427$ $\mathrm{nm}$ reported by Chauvire et al. (2015) is also seen in our UV-Vis-NIR spectra, which has not been assigned to any impurity. To learn more about these impurities, and others undetectable by UV-Vis-NIR absorption spectroscopy, we additionally used other sensitive tools, as shown below.

Table 1. Average chemical compositions of 2 blue spinel samples from Luc Yen, obtained by EMPA.

\begin{tabular}{|c|c|c|}
\hline & $\begin{array}{l}\text { Light cobalt blue } \\
\text { (LY-1) }\end{array}$ & $\begin{array}{c}\text { Saturate cobalt blue } \\
\text { (LY-2) }\end{array}$ \\
\hline \multicolumn{3}{|c|}{$\overline{\text { Oxides (wt } \%)}$} \\
\hline $\mathrm{V}_{2} \mathrm{O}_{3}$ & 0,07 & 0,08 \\
\hline $\mathrm{MnO}$ & 0,10 & 0,09 \\
\hline $\mathrm{NiO}$ & 0,08 & 0,23 \\
\hline $\mathrm{ZnO}$ & nd & 0,02 \\
\hline $\mathrm{Al}_{2} \mathrm{O}_{3}$ & 70,22 & 70,48 \\
\hline $\mathrm{TiO}_{2}$ & 0,01 & 0,01 \\
\hline $\mathrm{Cr}_{2} \mathrm{O}_{3}$ & 0,05 & 0,14 \\
\hline $\mathrm{FeO}$ & 0,71 & 0,50 \\
\hline $\mathrm{CoO}$ & 0,05 & 0,09 \\
\hline $\mathrm{MgO}$ & 28,07 & 27,65 \\
\hline $\mathrm{CaO}$ & nd & 0,01 \\
\hline Total & 99,35 & 99,29 \\
\hline \multicolumn{3}{|c|}{ Cation (4 Oxygen) } \\
\hline V & 0,001 & 0,002 \\
\hline $\mathrm{Mn}$ & 0,002 & 0,002 \\
\hline $\mathrm{Ni}$ & 0,002 & 0,004 \\
\hline $\mathrm{Zn}$ & 0,000 & 0,000 \\
\hline $\mathrm{Al}$ & 1,982 & 1,989 \\
\hline $\mathrm{Ti}$ & 0,000 & 0,000 \\
\hline $\mathrm{Cr}$ & 0,001 & 0,003 \\
\hline $\mathrm{Fe}$ & 0,014 & 0,010 \\
\hline $\mathrm{Co}$ & 0,001 & 0,002 \\
\hline $\mathrm{Mg}$ & 1,002 & 0,987 \\
\hline
\end{tabular}

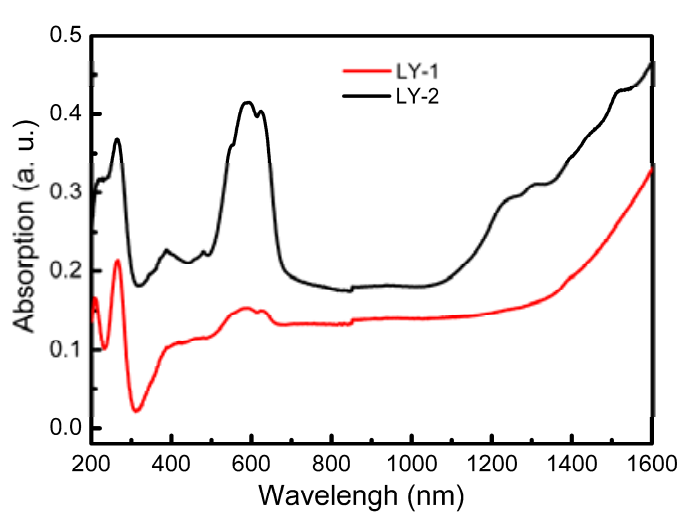

Figure 3. UV-Vis-NIR spectra of LY-1 and LY-2 showing the presence of $\mathrm{Co}^{2+}$ and $\mathrm{Fe}^{2+}$ ions. 
Vietnam Journal of Earth Sciences, 40(1), 47-55

\subsection{ESR analyses}

ESR is a resonant technique based on the microwave absorption of unpaired electron spins in an applied magnetic field $(H)$. The resonance occurs at the resonant field $\left(H_{\mathrm{r}}\right)$ as $h v=g / \mu_{\mathrm{B}} H_{\mathrm{r}}$, where $h, v, g$, and $\mu_{\mathrm{B}}$ are the Planck constant, microwave frequency, Lande factor, and Bohr magneton, respectively. This is proven to be a sensitive tool to study electronic structures, lattice defects, impurities, and magnetic phases of a material (Ikeya, 1993). For color centers (lattice defects and/or impurities) present in gemstones, depending on color-center types and oxidation states, their resonant spectra could be observed at low or room temperatures. Using this technique, we recorded room-temperature ESR spectra of the samples LY-1 and LY-2 (Figure 4). It appears that their spectral features are quite the same, with two resonant regions. The first region of 1650 1950 Oe shows a single line (the insets of Figure 4) with $H_{\mathrm{r}} \approx$ 1970 Oe, which is assigned to a $\mathrm{Cr}^{3+}$ forbidden transition $(\Delta M=2)$ (Padlyak et al., 2003). The other one of 3000 4000 Oe shows the sextet due to $\mathrm{Mn}^{2+}$ ions isolated in crystal fields of the $\mathrm{MgAl}_{2} \mathrm{O}_{4}$ structure (Ikeya, 1993). The spectral splitting (the distance between any two neighboring lines) is about 75 Oe. Originally, these lines are generated from the electron-nuclear interaction (i.e., the hyperfine structure) of $\mathrm{Mn}^{2+}$ that can be understood as follows: $\mathrm{Mn}^{2+}$ with the high-spin electron configuration $3 d^{5}$ has the spin numbers $S=5 / 2$ (electron spin) and $I=5 / 2$ (nuclear spin). Six energy levels $(2 M+1=6)$ of the electron spin with the magnetic quantum number $M= \pm 5 / 2$, $\pm 3 / 2$, and $\pm 1 / 2$ generated by an external magnetic field are further split by the magnetic fields due to six nuclear spin states $(2 I+1=$ $6)$ with the nuclear spin magnetic quantum number $m= \pm 5 / 2, \pm 3 / 2$, and $\pm 1 / 2$. This leads to the resonance at six different magnetic fields, corresponding to the allowed transi- tions $(\Delta M= \pm 1$ and $\Delta m=0)$ of $(-5 / 2,-3 / 2),(-$ $3 / 2,-1 / 2),(-1 / 2,+1 / 2),(+1 / 2,+3 / 2)$, and $(+3 / 2,+5 / 2)$ (Ikeya, 1993). The observation of these transitions depends on the crystal orientation versus the applied field direction. For the present samples in powder, we only observe the central transition of $(-1 / 2,+1 / 2)$, which is angular-independent of the crystal orientation.

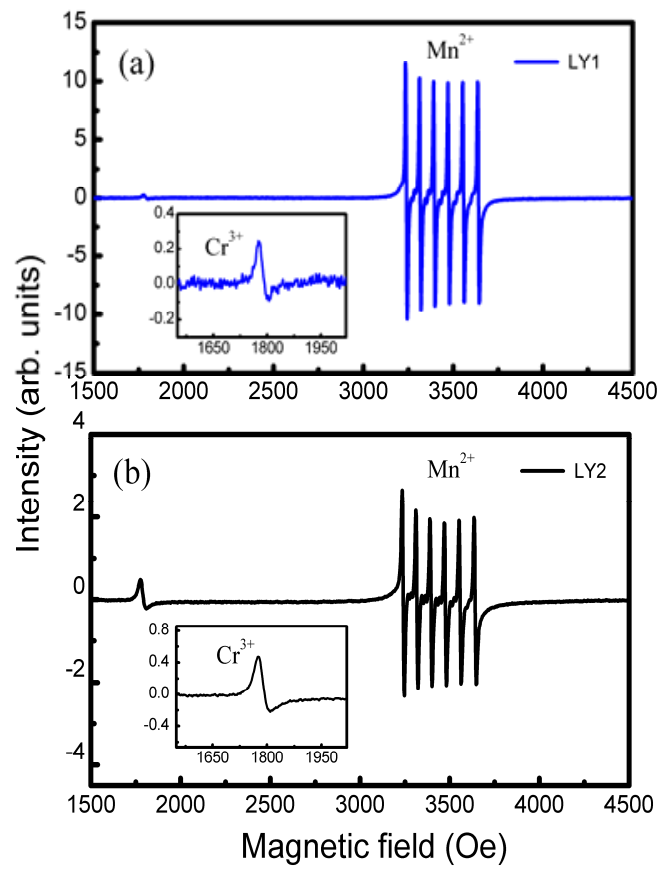

Figure 4. ESR spectra of the samples of (a) LY-1 and (b) LY-2, which show the presence of $\mathrm{Cr}^{3+}$ and $\mathrm{Mn}^{2+}$ ions. The insets show an enlarged view of the $\mathrm{Cr}^{3+}$ related spectral region

If more attention is given to the resonantsignal intensity, one can see that the intensity of the $\mathrm{Mn}^{2+}$ hyperfine lines in LY-2 is smaller than that of LY-1, proving less $\mathrm{Mn}^{2+}$ ions present in LY-2. However, the $\mathrm{Cr}^{3+}$ amount in LY-2 is higher than that in LY-1. These results are in good agreement with those recorded from the EMPA study, as shown in Table 1. Apart from $\mathrm{Mn}^{2+}$ and $\mathrm{Cr}^{3+}$ ions, the ESR investigation did not detect other impurities as 
found in the EMPA and UV-Vis studies because their resonant signal is invisible at room temperature or their concentration in the samples are out of the detection limit of the spectrometer. Notably, the ESR study found the presence of $\mathrm{Mn}^{2+}$ and $\mathrm{Cr}^{3+}$ ions, but could not identify their site in the spinel structure. We thus used another spectroscopic technique, as shown below.

\subsection{XAS analyses}

The study of how X-ray beams absorbed by an atom at energy levels near and above core-level binding energies is known as X-ray absorption fine structure (XAFS). It is related to chemical and physical states of the absorbing atom, and thus sensitive to valence state, bond lengths, and the coordination number of neighbor atoms (Teo, 1986). The study of matter based on XAFS provides important information on the atomic scale. Basically, each XAFS spectrum of an absorbing atom is divided into three characteristic regions: the preedge, X-ray absorption near edge structure (XANES), and extended X-ray absorption fine structure (EXAFS). The pre-edge region is related to transitions from core electrons to bound states, such as $1 s$ to $n d,(n+1) s$ or $(n+1) p$ orbitals for the $K$ edge. The XANES region gives information related to valence states of the absorbing atom. Different oxidation states result in a chemical shift in the absorption edge. For the EXAFS region, it is the sum of all outgoing and incoming waves, and dependent on the immediate environment surrounding the absorbing atom. EXAFS analysis thus gives information on the bond distances, geometric structure, and coordination number of neighbor atoms.

We performed XAFS experiments for the $K$ edge of elements Ti, V, Cr, Mn, Co, Fe, Zn and $\mathrm{Ni}$ present in a typical sample LY-2.
Among these elements, only XAFS spectra of $\mathrm{Cr}, \mathrm{Co}, \mathrm{Fe}$ and $\mathrm{Ni}$ were recorded clearly, as shown in Figure 5. The spectra of other elements (Ti, V, $\mathrm{Zn}$ and $\mathrm{Mn}$ ) were very weak, and undistinguishable from background noises, probably due to their low concentration, and/or their small emission energy absorbed by ambient air. Analyzing the XAFS spectra, we obtained the following results: (i) For element $\mathrm{Cr}$, the absorption edges of LY-2, $\mathrm{Cr}_{2} \mathrm{O}_{3}$ (containing $\mathrm{Cr}^{3+}$ ), and $\mathrm{Cr}^{3+}-\mathrm{MgAl}_{2} \mathrm{O}_{4}$ (red spinel), in the energy range 5990-6000 eV, overlap each other, see Figure 5(a). This proves that the oxidation state of $\mathrm{Cr}$ is $3+$. (ii) For element $\mathrm{Fe}$, the absorption spectra of LY-2, Fe foil $\left(\mathrm{Fe}^{0}\right)$ and $\mathrm{Fe}$-doped $\mathrm{LaMnO}_{3}$ (with a coexistence of $\mathrm{Fe}^{3+}$ and $\mathrm{Fe}^{2+}$ ) do not show any overlap at the $K$-edge in the range of 7105 $7130 \mathrm{eV}$, Figure 5(b), reflecting that the $\mathrm{Fe}$ oxidation state in LY-2 could not be $0,3+$ and $4+$. We found the absorption edge of $\mathrm{Fe}$ in LY-2 located at around $7117.5 \mathrm{eV}$, which is very close to that of $\mathrm{Fe}^{2+}$ in $\mathrm{FeO}$ (Nguyen et al., 2011). This means that $\mathrm{Fe}$ impurities in our LY-2 sample are $\mathrm{Fe}^{2+}$ rather than other states. (iii) For element $\mathrm{Co}$, we also recorded the XAFS spectra of $\mathrm{Co}$ foil $\left(\mathrm{Co}^{0}\right), \mathrm{CoO}$ $\left(\mathrm{Co}^{2+}\right)$, and $\mathrm{Co}_{3} \mathrm{O}_{4}\left(\mathrm{Co}^{2+}, \mathrm{Co}^{3+}\right)$ together with LY-2. The results shown in Figure 5(c) reveal the absorption edge of LY-2, in the range 7710-7717 eV, almost overlapping with that of $\mathrm{CoO}$, proving the existence of $\mathrm{Co}^{2+}$ ions in LY-2. Finally, for element Ni, the spectra in Figure 5(d) show the overlap of the absorption edges of LY-2 and $\mathrm{NiO}\left(\mathrm{Ni}^{2+}\right)$, demonstrating the presence of $\mathrm{Ni}^{2+}$ ions in LY-2; its concentration is quite small, leading to noisy signals at high energies far from the edge absorption. In short, detailed XAFS studies have provided a evidence that there coexist of $\mathrm{Cr}^{3+}, \mathrm{Fe}^{2+}$, $\mathrm{Co}^{2+}$, and $\mathrm{Ni}^{2+}$ ions in the sample LY-2. 


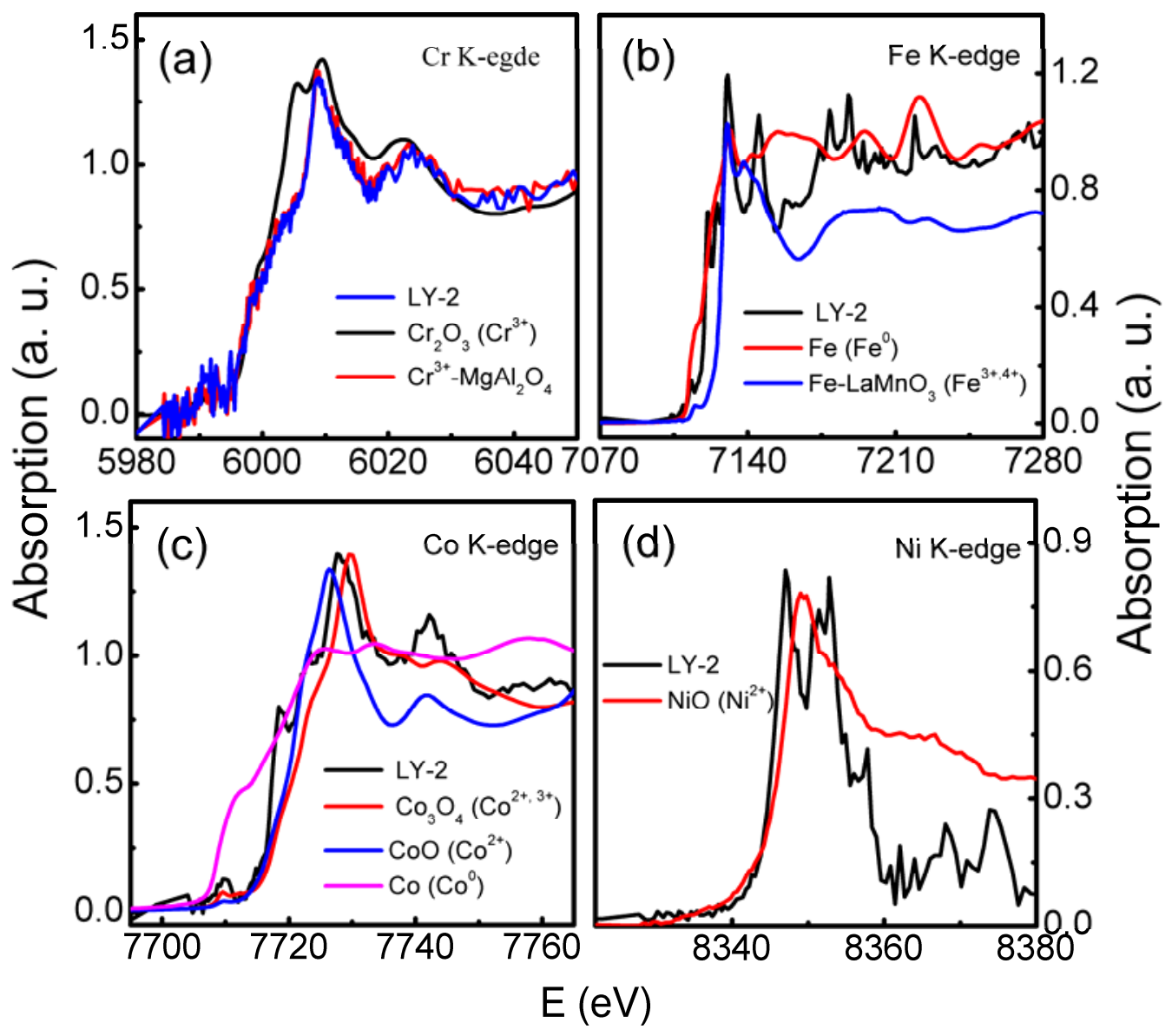

Figure 5. K-edge XAFS spectra of (a) Cr, (b) Fe, (c) Co, and (d) Ni dopants present in LY-2, compared with those of standard samples (foils or oxides)

Together with identifying impurities and their valence, we have taken into account their site in the $\mathrm{MgAl}_{2} \mathrm{O}_{4}$ spinel structure. This could be carried out in terms of performing the Fourier transform (FT) in the real space R for the EXAFS spectra (Teo, 1986). Here, we are only successful for the FT for the EXAFS data of the $\mathrm{Cr}$ and $\mathrm{Co}$; other elements have a poor profile of the EXAFS region. The FT spectra of the $\mathrm{Cr}$ and $\mathrm{Co} K$-edges are plotted in Figure 6. It appears from Figure 6(a) that the average bond length between $\mathrm{Cr}$ and $\mathrm{O}$, $R_{\mathrm{Cr}-\mathrm{O}}$, in the spinel LY-2 is about $1.46 \AA$. Meanwhile, the bond distance between $\mathrm{Cr}$ and
$\mathrm{Al}, R_{\mathrm{Cr}-\mathrm{Al}}$ is about $2.29 \AA$. These distances are very close to those between $\mathrm{Cr}$ with $\mathrm{O}$, and $\mathrm{Cr}$ with $\mathrm{Al}$ of a red spinel $\left(\mathrm{Cr}^{3+}: \mathrm{MgAl}_{2} \mathrm{O}_{4}\right.$, the reference sample). It should be noticed that $R_{\mathrm{Cr}-\mathrm{O}}$ and $R_{\mathrm{Cr}-\mathrm{Al}}$ values are shifted by $\sim 0.5 \AA$ on the $R$ axis from their true values because of the phase shift of backscattered photoelectrons. If considering the FT spectra of Co (Figure 6b), one also can see that the bond distances $R_{\mathrm{Co}-\mathrm{O}}$ and $R_{\mathrm{Co}-\mathrm{Al}}$ (dotted lines) are almost close to those of $R_{\mathrm{Cr}-\mathrm{O}}$ and $R_{\mathrm{Cr}-\mathrm{Al}}$ in the samples LY-2. Juhin et al. (2007) have studied $\mathrm{MgAl}_{2} \mathrm{O}_{4}: \mathrm{Cr}^{3+}$ samples (where $\mathrm{Cr}^{3+}$ substituted for $\mathrm{Al}^{3+}$ ) by using the XAS technique 
and theoretical calculation, and showed that the distances $R_{\mathrm{Cr}-\mathrm{O}}$ and $R_{\mathrm{Cr}-\mathrm{Al}}$ are $1.98 \sim 1.99 \AA$ and 2.88 2.91 $\AA$, respectively. These distances are in good agreement with our work results, as shown above, proving that both $\mathrm{Cr}^{3+}$ and $\mathrm{Co}^{2+}$ ions have the same position, and are located at the $\mathrm{Al}^{3+}$ site of the $\mathrm{MgAl}_{2} \mathrm{O}_{4}$ spinel.

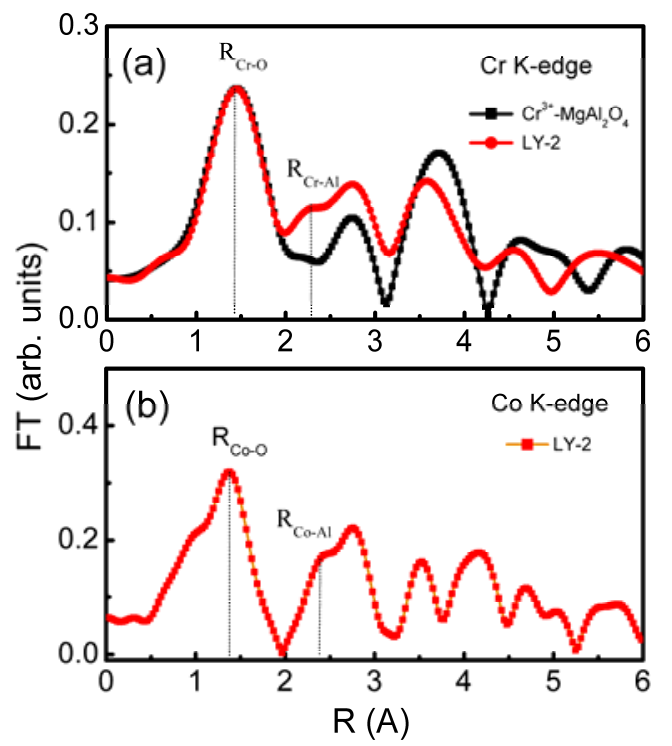

Figure 6. The FT spectra of LY-2 for (a) $\mathrm{Cr}$ and (b) $\mathrm{Co}$ $K$-edges comparing with $\mathrm{MgAl}_{2} \mathrm{O}_{4}: \mathrm{Cr}^{3+}$

\section{Discussions}

The presence of $\mathrm{Cr}^{3+}, \mathrm{Fe}^{2+}, \mathrm{Co}^{2+}, \mathrm{Mn}^{2+}$ and $\mathrm{Ni}^{2+}$ in $\mathrm{MgAl}_{2} \mathrm{O}_{4}$ were determined. Particularly, we identified the location of $\mathrm{Cr}^{3+}$ and $\mathrm{Co}^{2+}$ in the $\mathrm{Al}^{3+}$ site. In $\mathrm{MgAl}_{2} \mathrm{O}_{4}$ spinel structure, it has been believed that $2+$ ions $\left(\mathrm{Fe}^{2+}, \mathrm{Co}^{2+}\right.$, $\mathrm{Mn}^{2+}$, and/or $\mathrm{Ni}^{2+}$ ) occupy the $\mathrm{Mg}$ tetragonal (Chauviré et al., 2015; Gaft et al., 2005). However, it is now indicated that $\mathrm{Co}^{2+}$ could be also located in octahedral sites of spinel. In reference to the color of the samples LY-1 and LY-2, based on the features of UV-Vis spectra shown in Figure 3, we agree with the opinion that $\mathrm{Co}^{2+}$ ions are the main coloring agent for the cobalt-blue color (Chauviré et al., 2015). The saturate level of cobalt-blue color depends on $\mathrm{Co}^{2+}$ concentration. A lower $\mathrm{Co}^{2+}$ concentration in LY-1 compared with LY-2 makes the color of LY-1 brighter than that of LY-2. Apart from $\mathrm{Co}^{2+}$ ions, we believe that ions $\mathrm{Fe}^{2+}$ and $\mathrm{Cr}^{3+}$ also influence strongly the color of cobalt-blue spinel. For example, Chauvire et al. (2015) pointed out that a higher iron/cobalt ratio makes spinel grayer. With increasing $\mathrm{Cr}$ content, spinel changes the color from red to green (Juhin et al., 2007). For $\mathrm{Mn}^{2+}$ (and $\mathrm{Ni}^{2+}$ ) ions, they seem to contribute insignificantly to the color change of the samples because LY-1 has a higher $\mathrm{Mn}^{2+}$ content, but its cobalt color is lighter than LY-2.

\section{Conclusions}

Impurities present in light and saturated cobalt-blue spinel samples collected from Luc Yen mining area (Vietnam) have been studied in details. By using different techniques, including EMPA, UV-VIS-NIR, ESR and XAS, the existence of impurities $\mathrm{V}, \mathrm{Mn}, \mathrm{Ni}, \mathrm{Zn}, \mathrm{Ti}$, $\mathrm{Cr}, \mathrm{Fe}, \mathrm{Co}$, and $\mathrm{Ca}$ were identified. Among those impurities, the oxidation state of $\mathrm{Mn}$, $\mathrm{Co}, \mathrm{Fe}$ and $\mathrm{Ni}$ is $2+$, while that of $\mathrm{Cr}$ is $3+$. Based on the FT, we found that $\mathrm{Cr}^{3+}$ and $\mathrm{Co}^{2+}$ ions located at the $\mathrm{Al}^{3+}$ site of the $\mathrm{MgAl}_{2} \mathrm{O}_{4}$ spinel structure. We believe that the variation of cobalt-blue color is due to $\mathrm{Co}^{2+}, \mathrm{Fe}^{2+}$ and $\mathrm{Cr}^{3+}$, depending on their concentration. Other impurities $\left(\mathrm{Mn}^{2+}\right.$ and $\left.\mathrm{Ni}^{2+}\right)$ contributed insignificantly to the color variation of blue spinel.

\section{Acknowledgements}

This study is supported by a NAFOSTED project grants (105.99-2013.13).

\section{References}

D'Ippolito V., Andreozzi G.B., Hålenius U., Skogby H., Hametner K., Günther D., 2015. Color mechanisms in spinel: cobalt and iron interplay for the blue color. Physics and Chemistry of Minerals, 42, 431-439.

Chauviré B., Rondeau B., Fritsch E., Ressigeac P. and Devidal J.L., 2015. Blue spinel from the Luc Yen district of Vietnam, Gems \& Gemology, 51, 2-17.

Garnier V., Giuliani G., Ohnenstetter D., Fallick A.E., Dubessy J., Banks D., Vinh H.Q., L'homme T., Maluski H., Pêcher A., Bakhsh K.A., Long P.V., Trinh 
Vietnam Journal of Earth Sciences, 40(1), 47-55

P.T., Schwarz D., 2008. Marble-hosted ruby deposits from Central and South-East Asia: Toward a new genetic model. Ore Geology Reviews, 34, 169-191.

Gaft M., Reisfeld R., Panczer G., 2005. Modern luminescence spectroscopy of minerals and materials, Springer-Verlag Berlin Heidelberg, 96-97.

Giuliani G., Dubessy J., Banks D., Vinh H.Q., Lhomme T., Pironon J., Garnier V., Trinh P.T., Long P.V., Ohnenstetter D., Schwarz D., 2003. $\mathrm{CO}_{2}-\mathrm{H}_{2} \mathrm{~S}-\mathrm{COS}$ $\mathrm{S}_{8}-\mathrm{AlO}(\mathrm{OH})$-bearing fluid inclusions in ruby from marble-hosted deposits in Luc Yen area, North Vietnam. Chemical Geology, 194, 167-185.

Ikeya1 M., 1993. New Applications of Electron Spin Resonance, World Scientific Publishing, 34-57.

Juhin A., G. Calas, D. Cabaret, L. Galoisy and J. L. Hazemann, 2007. Structural relaxation around substitutional $\mathrm{Cr}^{3+}$ in $\mathrm{MgAl}_{2} \mathrm{O}_{4}$. Physical Review B, 76, 54-105.
Nguyen H.M., Dang N.V., Chuang P.Y, Thanh T.D., Hu C.W, Chen T.Y., Lam V.D., Lee C.H., Hong L.V., 2011. Tetragonal and hexagonal polymorphs of $\mathrm{BaTi1}_{-\mathrm{xFexO}}-\delta$ multiferroics using x-ray and Raman analyses. Applied Physics Letters, 99, 202-501.

Leloup P.H., Arnaud N., Lacassin R., Kienast J.R., Harrison T.M., Trinh P.T., Replumaz A., Taponnier P., 2001. New constraints on the structure, thermochronology, and timing of the Ailo Shan-Red River shear zone, SE Asia. Journal of Geophysical Research, 106, 4, 6683-6732.

Padlyak B.V., Grinberg M., Lukasiewicz T., Kisielewski J., Swirkowicz M., 2003. EPR spectroscopy of the $\mathrm{Cr}^{3+}$ centers in LLGG:Cr single crystals. Journal of Alloys Compounds, 361, 6-12.

Shigley J. E. and Stockton C. M., 1984. Cobalt-blue gem spinels. Gems \& Gemology, 20, 34-41.

Teo B.K., 1986. EXAFS: Basic principles and data analysis, Springer-Verlag. 